\title{
A MOOC-based Flipped Classroom Model: Reflecting on pre-service English language teachers' experience and perceptions
}

\author{
Muhammed Özgür YAŞAR* \\ Eskişehir Osmangazi University, Education Faculty, English Language Teaching \\ Department, Eskişehir, Turkey \\ ORCID: 0000-0002-7167-2192
}
Mustafa POLAT
Bahcesehir University, Education Faculty, English Language Teaching Department, İstanbul, Turkey

ORCID: 0000-0001-9803-2833

\begin{tabular}{l}
\hline \hline Article history \\
\hline Received: \\
22.10 .2020 \\
Received in revised form: \\
17.03 .2021 \\
Accepted: \\
28.03 .2021 \\
Key words: \\
\hline Flipped classroom; \\
EFL learners; \\
Pre-service English language \\
teachers; \\
MOOC; \\
Connectivism
\end{tabular}

The flipped classroom (FC) model has recently gained an increasing interest in higher education. Similarly, Massive Open Online Courses (MOOCs) have attracted international attention in the literature. However, a review of previous studies suggests that although a MOOCbased FC model has often been advocated in theory, it has consistently been disregarded in practice. Therefore, the main significance of this study lies in its implementation of a MOOC-based FC model in an English Language Teaching (ELT) program for pre-service English language teachers for the first time in a Turkish context, and also in the literature. Moreover, the study explores pre-service teachers' perceptions of a MOOC-based FC model and its effects on their academic achievement. In this regard, the study provides an exciting opportunity to advance our knowledge of the MOOC-based FC model in teacher education, especially in the field of ELT. The study took place at a state university in Turkey with 27 pre-service English language teachers in the 2019-2020 academic year. The methodological approach adopted in this study was a mixed-methods research design, benefiting from both quantitative and qualitative data collection techniques. It followed a preexperimental research design, involving the One-Group Pre-test - Posttest Design. A four-week intervention of MOOC-based FC implementation took place between the pre-test and the post-test. Taking the findings of this study into account, some stakeholders, e.g., educators, teacher trainers, policymakers, administrators, and other professionals might consider integrating a MOOC-based FC model into the traditional classroom settings or creating a blended course that incorporates a MOOC into their existing face-to-face programs.

\footnotetext{
*Correspondency: muhamedozgury@gmail.com
} 


\section{Introduction}

The widespread use and availability of the Internet, the greater variability in web technologies and the incredible increase in the use of computers have brought various considerable changes in education. Similarly, the rapid advancement in information and communication technology has necessitated the introduction of new learning technologies and modern pedagogical methods, which could promote collaborative learning and provide continuous access to knowledge even before and after class time.

Proposing his theory of connectivism as a net-based learning phenomenon enabling learning with technological and social networks, Siemens (2005) developed it further claiming that learning should be linked up in networks to facilitate the interconnectivity of social networks, thus bringing up together a wide range of target groups with the active involvement of the social partners. Defining these social partners as a network of connections between entities, and calling these entities nodes, which he referred to as groups, systems, individuals, communities, and social networks, Siemens (2005) spoke of the connectivism theory as a direct descendant of behaviorism, cognitivism, and constructivism. However, seeking evidence in favor of his theory, Siemens (2005) criticized the existing traditions for being "limited due to their intrapersonal view of learning, their failure to address the learning that is located within technology and organizations, and their lack of contribution to the value judgments that need to be made in knowledge-rich environments" (Goldie, 2016, p. 1064).

This being said though, it is not that there are no arguments against connectivism. Kropf (2013), for example, referred to connectivism as an instructional theory, rather than a learning theory, proposing that "an instructional theory is a conceptual framework based on empirical findings and grounded in learning theories, which recommends the design of learning materials, resources, or situations to help learners achieve their learning outcomes and maximize their learning potential" (p. 15). Similarly, Kop and Hill (2008) consider that connectivism is not a learning theory, rather it is more appropriate to assess it from a pedagogical perspective. However, "connectivism provides a framework for understanding learning that is especially pertinent in the context of information literacy education" (Dunaway, 2011, p. 683).

With their progressive pedagogical aspects that put into practice the basic principles of connectivism theory, Massive Open Online Courses (MOOCs) enable individuals to become active learners by facilitating relationships and networks of people through the efficient use of shared resources, opened files, and connected users, who can shape and build their learning (Cormier, 2008). Some specific features of MOOCs such as accessibility, affordability, openness and convenience, from Yaşar's (2020) perspective, “make it possible for a person's message to make its way around the globe to eventually end up back to the same person after being responded and commented by innumerable participants across borders" (p. 9).

Similarly, with its pre-prepared, out of class lectures and in-class sessions which respectively combines the elements of behavioristic (mainly teacher-centered contents) and constructivist (student-centered instruction) learning theories, the Flipped Classroom (FC) model, which is defined as "a pedagogical approach in which direct instruction moves from the group learning space to the individual learning space, and the resulting group space is transformed into a dynamic, interactive learning environment where the educator guides students as they apply concepts and engage creatively in the subject matter" (Flipped Learning Network, 2014), is consistent with connectivist principles as it also utilizes online network learning by integrating a MOOC in face-to-face traditional classroom instruction, thus promoting the fullest possible social integration and interpersonal communication through the interactivity of the MOOC. 
Combining the elements of online and face-to-face learning by incorporating a MOOC in a traditionally taught course, the MOOC-based FC instructional model in the current study shares the principles of connectivist theory as learning and content delivery that extend beyond the boundaries of the classroom with multiple ways of learning such as globally connected online communities on the MOOC, social networks on the Web, face-to-face traditional classroom instruction, online and offline interaction with peers and instructors. As a consequence, substantially enriched with online learning resources and an active global online community, the MOOC-based FC approach promotes an effective combination of in-class, online and hybrid delivery formats and enhances learner interaction and cooperation by allowing students to become active learners in ways that are consistent with connectivist principles. Therefore, supplementing traditionally taught classes or replacing some in-class components with highquality online content and interactive e-learning modules has become a critical issue.

Taking into account the concept of blended learning, a new model for organizing educational programs especially in higher educational institutions and a phenomenon combining face-toface teaching with E-learning practices, many researchers and educators around the world have started to provide guidelines for instructors to integrate MOOC content into the traditional faceto-face classroom teaching (de Jong et al., 2020). Similarly, advocating that FC practices that are based on principles of learner-centered learning and online video presentations would improve the overall learning outcomes, educational practitioners are arguing that FC model allows learners to be more active in their learning, thus letting them engage in active learning (Strayer, 2012). Being based on the constructivist approach, "the FC model promotes understanding instead of rote learning, active construction of the knowledge instead of passive transmission and reception of the information, and social interaction and cooperation instead of the teacher-centered learning environment" (Akçor, 2018, p. 18).

Combining the FC model, which promotes a learner-centered learning environment and active learning processes with digitally-enhanced MOOCs, which extends learning beyond the walls of conventional classrooms, the MOOC-based FC model merges the major elements of online and face-to-face learning (Jitpaisarnwattana, Reinders, \& Darasawang, 2019). The MOOCbased FC model is, therefore, grounded in connectivism, as according to the theory "learning in the digital age is mostly dependent on the connection of learners with various sources of knowledge from the Internet and the interaction with others in communities or social networks" (Yin, 2016, p.20).

Although a MOOC-based FC model has often been advocated in theory, it has consistently been disregarded in practice, so the main significance of this study lies in its implementation of a MOOC-based FC model in an English Language Teaching (ELT) program for pre-service English language teachers for the first time in a Turkish context, and possibly in the literature. Therefore, the importance and originality of this study are that it explores pre-service English language teachers' perceptions of a MOOC-based FC model and its effects on their academic achievement. It also seems to be significant as it is likely to offer valuable insights into preservice English language teachers' overall views on integrating a MOOC-based FC model into the ELT program. Finally, the significance of this study is also evident through the detailed description of the pre-service English language teachers' perceptions of the MOOC-based FC model, which could provide valuable opportunities and information for researchers, practitioners, pre-service teachers, in-service teachers, educators, teacher trainers, policymakers, administrators and other professionals by setting a clear example for them to decide if this instructional model could be a practical alternative to classical face-to-face lectures. Taking the findings of this study into account, some of these stakeholders might 
consider integrating a MOOC-based FC model into their traditional classroom settings or creating a blended course that incorporates a MOOC into their existing face-to-face programs.

\section{Literature Review}

In the literature on FC, there seem to be studies with an experimental design that have found significant differences in students' performances in favor of FC (Deslauriers \& Wieman, 2011; Fattah, 2017; Hung, 2015; Karimi \& Hamzavi, 2017; McLaughlin et al., 2014; Turan \& Akdag-Cimen, 2019; Yestrebsky, 2016). There are, however, experimental studies in the literature that have found no significant effect of FC on students' academic performance (Davies, Dean, \& Ball, 2013; Findlay-Thompson \& Mombourquette, 2014; Johnson \& Renner, 2012; Love, Hodge, Grandgenett, \& Swift, 2014). Hence, although only scant research is currently available on the effectiveness of FC, this little research yielded mixed results as regards its efficacy.

Al-Zahrani (2015) also studied the effect of FC on pre-service teachers participating in an elearning course. The participants reported a positive impact of FC on their creativity and higherorder thinking skills. Similarly, Vaughan (2014) explored the impact of flipped instruction on pre-service teachers in an introductory teaching course. The findings suggest an increased sense of responsibility on the part of students together with increased awareness of instructional strategies.

Sherrow, Lang, and Corbett (2016) also found in their study where they explored the impact of the FC model on a business communication course that there was an increase in school attendance and in the performance of students thanks to the increased interaction with peers, engaging collaborative tasks, and extended in-class time for practice. Several studies have also confirmed that the FC environment promotes participation and active engagement amongst students (Al-Zahrani, 2015; Elmaadaway, 2018; Steen-Utheim \& Foldnes, 2018). Having investigated the relationship between the FC approach and learning styles, a number of studies in the literature indicated that FC has more advantages for different learning styles of students than Traditional Classroom (TC), and those studies also revealed that FC instructional practices develop a greater awareness of different learning and teaching styles both at home and in the classroom (Strohmyer, 2016; Zappe et al., 2009).

Based on Siemens' (2005) connectivism, MOOCs promote active learning strategies and facilitate continual learning. Similarly, the findings of many research papers have made it clear that active learning strategies enhance learner's participation and motivation for learning in the flipped classroom model, which includes traditional classroom environments and online networks (Yilmaz, 2017). As its theoretical foundations are based upon the basic principles of connectivism learning theory, the current study also examines students' perceptions of the MOOC-based FC instructional model on the basis of connectivist principles.

A series of studies on the various aspects of MOOC-integrated flipped classroom courses have been conducted to evaluate the benefits and challenges of incorporating MOOCs in traditionally taught courses. Emerging as an alternative option to the many blended learning programs, the MOOC blend has been the focus of a few studies and scientific debates recently. Some examples of such studies are highlighted below.

Bruff, Fisher, McEwen, and Smith (2013) experimented on a blended course design, integrating a Coursera Machine Learning MOOC (hosted by Stanford University) into a graduate-level course on machine learning. Overall, student response to the MOOC blend was positive, 
describing the MOOC as useful thanks to its flexibility and accessibility, which enhance rapid and self-paced learning, especially through its bite-size videos. All in all, although the students appreciated the instructional design offered through the MOOC and valued the FC model as they rated the blended approach with a higher satisfaction score than the traditionally taught course, they acknowledged that it takes a lot of motivation and determination to stay focused and keep on track to achieve your learning goals.

Another study, piloting a MOOC blend concept, at San José State University (SJSU) was conducted by Ghadiri et al. (2013). The MOOC platform was provided by edX, which hosted the "Circuits and Electronics" course. The results revealed a high success rate with $90 \%$ of the participants passing the final exam, as compared with 55\% in the TC of the past year, clearly reflecting a high degree of academic achievement. Despite these positive results, however, there were still some open issues, including lack of interaction between learners and the video content, in addition to the insufficient integration between the MOOC platform and the Learning Management System (LMS) of the campus.

Based on their research findings, Yousef et al. (2015) noted several limitations of MOOCs, including "following a teacher-centered and centralized learning model, the lack of effective assessment and feedback, the lack of interactivity between learners and the video content, the diversity of MOOC participants, and the absence of face-to-face interaction" (p. 90). However, based on the findings of their research study, the purpose of which was to design, conduct, and evaluate a MOOC-integrated FC course on "Teaching Methodologies" at Fayoum University in Egypt, there is broad consensus among participants that integrating MOOCs in traditionally taught courses can overcome the limitations of MOOCs listed above.

Song, Song, and Wei (2015) conducted a study, using a MOOC-based flipped classroom model for college English teaching in China. The results of the study demonstrated that the FC based in a MOOC improves students' problem-solving skills, innovative thinking skills, independent study, and team cooperation. Another result of the study, however, was that an effective and rigorous monitoring method should be implemented and actively pursued by instructors to ensure course success.

Xinying (2017) carried out a research study, involving 800 students at Shenzhen University. Students were taking Level-A college English Reading and Writing course. Participants' perceptions of the MOOC embedded FC teaching model was explored based on analysis of the survey results after a one-year experiment. The results provided convincing evidence in favor of the flipped model. The findings indicated that the participants highly valued the MOOC embedded flipped approach, believing that they were making good progress towards improving their general level of English.

Orsini-Jones, Conde Gafaro, and Altamimi (2017) carried out a study at Coventry University, where the FutureLearn MOOC Understanding Language: Learning and Teaching was integrated into the curriculum of the Master of Arts (MA) in ELT program. The results revealed a noticeable shift in participants' beliefs on online learning, suggesting, on the whole, a positive view on the MOOC blend experience. The participants indicated that the MOOC was an effective open educational addition to the Moodle platform, stressing that they liked the convenience in the access to extra materials provided by the MOOC. Speaking of the blended aspect of the study, most of the students recommended that MOOCs should be made more broadly accessible and they should be integrated into more modules. With regard to negative aspects, on the other hand, the participants reported a large number of postings after each topic, 
making it difficult for them to navigate MOOC discussions.

More recently, in a similar study within the same program, Phi (2018) examined how the beliefs of an MA in ELT student at Coventry University and his identity as an autonomous teacher were affected by a blended MOOC approach. The findings revealed that the MOOC blend changed his perception of online and blended learning, transforming his skepticism into a firm belief that a MOOC blend can promote autonomy. The participant also noted that blending MOOCs into existing curricula can enhance autonomous pedagogical teaching approaches.

Consequently, all these above-mentioned studies contribute to our understanding of how the use of MOOCs and the FC model could bring considerable changes in education systems. They also prove that supplementing the FC model with high-quality MOOC content should be on the agenda of all educators and practitioners. This goes to show that there is an urgent need to conduct studies that could set as examples for all stakeholders to decide if a MOOC-based FC model could be a useful alternative to classical face-to-face lectures. However, before profound changes or radical reorganizations can be implemented, all stakeholders should be provided with some data regarding the effect of the MOOC-based FC model on the academic achievement of the learners, their perceptions of the model, and their overall attitudes towards the integration of the model into their existing face-to-face programs, which is within the scope of the present study. Hence, the following research questions guided the study:

(1) What is the impact of the MOOC-based FC Model on the pre-service English language teachers' academic performance?

(2) What are pre-service English language teachers' perceptions of integrating a MOOCbased FC model into the ELT program?

\section{Methodology}

\section{Research design and participants}

The first research question is addressed to see the impact of the MOOC-based FC Model on the achievement of the students within the experimental group, using convenient sampling. It would provide the readers with a deeper insight into the factors that determine the success of the model to have a control group in the current study, however as the first research question is mainly concerned with the gained scores of the experimental group, there is no control group in the current study.

The methodological approach adopted in this study was a mixed-methods research design, benefiting from both quantitative and qualitative data collection techniques. Lacking a control group, it followed a pre-experimental research design, involving the One-Group Pre-test - Posttest Design, where the administration of a pre-test, an intervention, and a post-test is only applied to a single group of participants (Campbell \& Stanley, 1963; Faulkner \& Taylor, 2005). Two open-response questionnaires were also used for data collection.

The current study took place at a state university in Turkey with pre-service English language teachers taking the "Learning Technologies in ELT I" course in the 2019-2020 academic year. Selected through convenience sampling, a non-random sampling method, the participants' ages ranged from 22 to 25 , and they were made up of 27 participants (16 female and 11 male). They were all required to register for a four-week online course, thereby engaging with a face-to-face teaching model blended with a MOOC. Offered free on FutureLearn, with the title of "Teaching 
English Online" (Appendix A), the course was developed by Cambridge Assessment English (FutureLearn, 2019). The content of the MOOC (Appendix B), which comprises four chapters of the coursebook, was in line with the traditional face-to-face course content, so it was integrated with the course curriculum. The FutureLearn MOOC Teaching English Online was integrated into the compulsory Learning Technologies in ELT I course curriculum for the experimental group. The type of the MOOC blend implemented in this study is what Sandeen (2013) refers to as 'MOOC 3.0' or a 'distributed flip' model, wherein the content of a MOOC is not developed by the education institution itself, but rather is provided by an external network of suppliers and becomes an integral part of the core curriculum.

A MOOC-based FC teaching model was implemented during the course period. The online course required 5 hours of study weekly. Learners were required to actively participate in collaborative tasks, get involved in online exercises and learning activities, and share their course work and reflections on a weekly basis on the Open Moodle Platform of the university during each week over the four-week duration of the MOOC platform. As part of the FC approach, students were required to study the course content for 3 hours individually on the FutureLearn MOOC. In the remaining 2 hours, course content was covered in a traditional faceto-face class format. The face-to face lecture was based on active, collaborative, and complementary tasks. The course on the MOOC platform was delivered by two professional online English teachers, while the complementary face-to-face course was offered by the researcher of this study. The participants were tested at the end of the four-week / 20-hour course, and their scores had a rate of 40 percent on their final score.

\section{Instruments}

To assess participants' academic achievement, a test ${ }^{1}$ by Cambridge Assessment English (2019) was administered twice before and after the educational intervention as a preand post-test. In addition, to explore students' perceptions about integrating a MOOC-based FC model into the ELT program, qualitative data were obtained via two open-response questionnaires. The first open-response questionnaire included 3 questions (see Appendix C) and the second one consisted of 3 questions (see Appendix D). Adapted from Amiryousefi (2019) and Chen Hsieh, Wu, \& Marek (2017), the first and second open-response questionnaires were collected based on Heigham and Crocker's (2009) guidelines. While the first open-response questionnaire was carried out with all participants right after the four-week intervention period was over, the second open-response questionnaire was administered to 7 participants 1 week later, mostly based on the content analysis done in the first open-response questionnaire. Therefore, additional clarification and more detailed information were provided. Table 1 below shows details about the sampling criteria of the qualitative data collection procedure.

Table 1. Overview of the Qualitative Data Sampling( $2^{\text {nd }}$ Open-Response Questionnaire $)$

\begin{tabular}{lllll}
\hline Participants & Gender & Pre-test Scores & Post-test Scores & Opinion on FC Model \\
\hline P1 & F & 87 & 100 & Positive \\
P2 & M & 74 & 96 & Positive \\
P3 & M & 81 & 96 & Negative
\end{tabular}

${ }^{1}$ The test (Teaching English Online Achievement Test) was comprised of 32 multiple choice questions. The test being used commercially, its items are not shared in this study. 


\begin{tabular}{lllll} 
P4 & F & 65 & 96 & Positive \\
P5 & F & 59 & 68 & Negative \\
P6 & F & 62 & 68 & Positive \\
P7 & M & 43 & 59 & Positive \\
\hline
\end{tabular}

\section{Procedure}

The study was conducted over a 4-week period. All aspects of the flipped model of teaching were covered. The students were informed that while in the face-to-face session extended classroom discussions would take place, and the content delivery would occur through the MOOC platform.

As explained above, each lesson followed a blended kind of teaching, which is required by the FC model. In other words, the learners got engaged in the course content through the MOOC platform at home, and then participated in the classroom activities and discussions, which were designed and coordinated by the instructor to reinforce and consolidate the content delivered in the MOOC platform. The engagement of the students was not limited to the class time, rather they continued to interact and engage in the learning content through the online MOOC platform. They also had the opportunity to extend their questions to the qualified teachers who were the developers of the online course. The students sometimes took notes and brought them up to the classroom to be discussed, which also helped them increase the retention of their knowledge and reinforce the subjects that were covered online and during the face-to-face session. All chapters followed this path.

\section{Data Analysis}

To achieve methodological variety, a combination of quantitative and qualitative data analysis procedures was carried out in this study. While quantitative data were provided through pre- and post-test results, qualitative data were obtained via two open-response questionnaires.

The quantitative data analysis was performed using SPSS 24. As regards the first research question, mean scores of the pre- and post-tests were evaluated to compare the statistical differences before and after intervention. Then, a normality test was conducted to check if the data set is normally distributed. Table 2 below shows data to be normally distributed ( $p>.05)$. The data having followed a normal distribution, a paired-samples t-test was carried out to see if a significant difference existed between students' pre- and post-test scores.

Table 2. Tests of normality

\begin{tabular}{lllllll}
\hline \multirow{2}{*}{ Compared Test Results } & \multicolumn{3}{l}{ Kolmogorov-Smirnov } & \multicolumn{3}{l}{ Shapiro-Wilk } \\
\cline { 2 - 7 } & Statistic & df & Sig. & Statistic & df & Sig. \\
\cline { 2 - 7 } & .123 & 27 & .200 & .970 & 27 & $\mathbf{. 5 9 8}$ \\
\hline
\end{tabular}

$* p>.001$.

Qualitative data analysis was conducted using content analysis, which was in line with van Manen's (2016) analysis criteria. First, data gathered through email from each participant were evaluated intensively. Then, after recurrently being read, each response was examined carefully to define key themes and categories. Next, thematic analysis was conducted by highlighting relevant parts and discarding data that were irrelevant. Then, based on the categorization of the most significant statements, core themes were formulated. 


\section{Findings}

\section{Findings related to the $1^{\text {st }}$ research question.}

The first research question aimed to find out the impact of the MOOC-based FC Model on the pre-service English language teachers' academic performance. Quantitative analyses were run to answer the first research question below.

$1^{\text {st }}$ Research question: What is the impact of the MOOC-based FC Model on the preservice English language teachers' academic performance?

Descriptive statistics comparing the pre- and post-test scores (see Table 3) of the participants before and after the treatment showed that the mean score of the post-test $(M=$ $84,48, S D=10,39)$ was higher than that of the pre-test $(M=64,22, S D=11,26)$.

Table 3. The Means of the Pre- and Post-test Scores.

\begin{tabular}{llll}
\hline Test & N & M & SD \\
\hline Pre-test & 27 & 64,22 & 11,26 \\
Post-test & 27 & 84,48 & 10,39 \\
\hline
\end{tabular}

The data having been normally distributed (see Table 2), parametric tests were applied. Hence, a paired-samples t-test was conducted to see if the difference between the two tests is significant. The paired-samples t-test indicated in Table 4 revealed that the participants performed significantly better on the post-test $(M=84.48, S D=10.39)$ compared to the pretest $(M=64.22, S D=11.26), t(26)=12.34, p<.001$, suggesting that the MOOC-based FC Model have a significant effect on pre-service English language teachers' academic performance.

Table 4. Paired-samples t-test

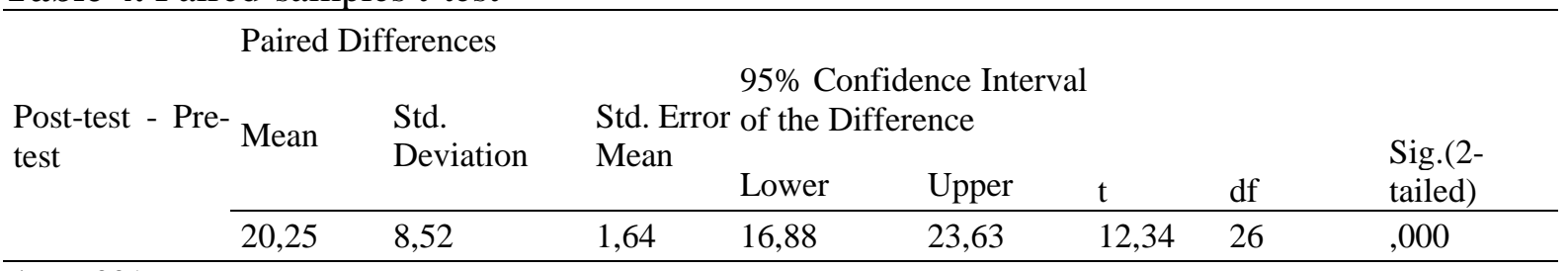

$* \mathrm{p}<.001$.

\section{Findings related to the $2^{\text {nd }}$ research question.}

The second research question aimed to explore pre-service English language teachers' overall opinions on integrating a MOOC-based FC model into the ELT program. The data collected from two open-response questionnaires were examined and the findings were presented in sufficient depth to provide an answer to the second research questions below.

$2^{\text {nd }}$ Research question: What are pre-service English language teachers' perceptions of integrating a MOOC-based FC model into the ELT program?

To assess the opinions of the students, data were processed, interpreted, and evaluated using qualitative analysis. Diverse views were put together upon being clustered to formulate some key themes. Table 5 below indicates the core themes revealed after further analysis. 
Table 5. Emerging Themes of the Qualitative Findings Related to the $2^{\text {nd }}$ Research Question

(a) expanded opportunities for a well-rounded education,

(b) expectations for immediate support and unwillingness to take extra personal responsibilities, and

(c) alternative teaching strategies for different learning styles and content-related factors.

(a) Expanded opportunities for a well-rounded education. When asked about their views on integrating a MOOC-based FC model into the ELT program, some of the participants commented that this could be a good idea as it provides them with a well-rounded combination of course content and practice through the MOOC platform and classroom instruction, as can be understood from the quotes below:

[...] I'II use flipped learning because I believe that practice is more important than the presentation of the language. Instead of teaching the students a new topic for hours and then giving them few activities, I prefer making them discover the language independently and creating a learning environment (MOOC) that includes lots of tasks and materials (Participant 4).

Despite agreeing that it is an effective way to reinforce the subjects in the curriculum and that it enhances the learning process, there were also some other respondents who stated that the integration of a MOOC-based FC model into the ELT program should be free from obligation, and its integration should be offered as an additional or alternative option to the TC model, instead of completely replacing it, as is clearly indicated in the excerpts below:

[...] Yes, it (the MOOC-based FC model) has so many benefits and it allows you to control your own learning, but only some of the courses should be adapted as a flipped classroom (Participant 3).

There were also some students who stated that they would like the MOOC-based FC model to be integrated into their ELT program as firstly, it is more effective and, secondly and more importantly, more motivating. However, they also shared their concerns about the role of the instructors, stressing that if the instructors do not feel ready to do their job with dedication and devotion, have little or no interest in implementing the MOOC-based FC model, have low motivation, or fail to fulfill their obligations arising from their reluctance to perform their daily tasks, the FC model should not be integrated, as can be understood from the comments below:

[...] I wish my other courses would be flipped as well in the ELT curriculum, but some instructors might take all the weight off their shoulders and put it on the students' shoulders (Participant 6).

A few participants also noted that despite the advantages of the FC model, they would still prefer the TC model due to the fact that they are used to the conventional classes and that they do not $t$ want to experience a new method on their last year, as understood from the comments below:

[...] I wish my other courses would be flipped as well in the ELT curriculum, but some instructors

According to the findings presented above, students are confident that the model can offer them a well-rounded education and can contribute to their academic and social development. 
Although they have some concerns about the role-adoption process of their instructors and the implementation of the model, they seem to hold positive views about the prospects of the model.

(b) Expectations for immediate support and unwillingness to take extra personal responsibilities. A few of the participants commented that maybe not all of them but some of the courses could be too difficult for them to grasp without immediate professional guidance provided by professors at the university, so they remained cautiously optimistic in their outlook toward the idea of integrating a MOOC-based FC model into the ELT program, as stated in the excerpts below;

[...] Some courses need conventional learning because the topics are so hard that you need immediate support, but some of them are suitable for flipped learning (Participant 4).

Few among the participants, however, were completely against the idea of integrating a MOOCbased FC model into the ELT program, implying that this integration would bring with it extra responsibilities, as can be inferred from the comment below:

[...] To be honest, I do not want it. I want lecture-based, traditional, teacher-led instructions. Also, in a flipped classroom, you have to rely on yourself. Collaboration with other students is difficult. I prefer the conventional learning approach (Participant 3).

Some participants also indicated that the MOOC-based FC model would mean a more intensive course content, compulsory self-learning programs, extra workload, and a greater effort, which would be required to achieve all the expected learning outcomes, thereby implying that they would not like to undertake such a heavy burden of demanding and multiple tasks, as understood from the quotes below:

[...] I prefer the conventional one because now it seems easier than flipped learning. Also, I feel undisturbed while taking lessons in a conventional way (Participant 5).

It seems that although their views show clear evidence of the efficacy of the model, some participants are guilty of serious neglect of duty and tasks that are required by the MOOC-based FC model, either because they fail to take new responsibilities or as they suffer just from sheer neglect.

(c) Alternative teaching strategies for different learning styles and content-related factors. Quite a few of the participants put forward the argument that the issue of integrating the MOOCbased FC model into the ELT program should be dependent on student preferences for specific learning styles, as some teaching methods might suit some learners, but not others. In addition, a successful teaching method or a tightly specified course content cannot serve all learning styles, so tailoring the content for individual learning styles and responding to different learning styles is likely to provide the best learning outcomes. This can be inferred from the excerpts below;

[...] I would first look for my students' needs and interests and after that, I would choose the best approach. In my opinion, insisting strictly on just one approach is not effective for some learners and the lesson itself (Participant 3).

When the comments of the participants are considered as a whole, it can be suggested that 
despite some concerns regarding students' readiness to fulfil their changing roles, the lack of training and insufficiency of instructors in adapting to new requirements, the views of the participants seem to be generally positive on the idea of integrating a MOOC-based FC model into the ELT program.

\section{Discussion}

\section{Discussion of findings for the $1^{\text {st }}$ research question}

The first research question aimed to investigate if the impact of the MOOC-based FC model on the pre-service English language teachers' academic achievement. The quantitative results revealed that the MOOC-based FC model had a significant effect on pre-service English language teachers' academic achievement. There are studies that have similar results with the present study (Deslauriers \& Wieman, 2011; Fattah, 2017; Hung, 2015; Karimi \& Hamzavi, 2017; McLaughlin et al., 2014; Turan \& Akdag-Cimen, 2019; Yestrebsky, 2016). Contrary to the findings of the present study, however, there are also some studies, which have revealed that the flipped-class instruction does not have a significant effect on students' performances (Davies, Dean, \& Ball, 2013; Findlay-Thompson \& Mombourquette, 2014; Johnson \& Renner, 2012; Love et al., 2014). Results from other research groups also suggest that traditional methods still need to be used as all topics cannot be covered with a flip-class approach (Johnson \& Renner, 2012; Ramlogan, Raman, \& Sweet, 2014; Snowden, 2012).

The success of the students in the present study could be attributed to the multiple tasks such as interacting with other participants, watching videos, joining discussion sessions and the like. This explanation broadly supports that of Strayer (2012), who found that the students in FC became more open to cooperative learning although there was no significant difference in their performance, and it also supports the findings of Findlay-Thompson and Mombourquette (2014), who received satisfactory responses from the students in FC with regards to the increased opportunities to ask questions during in-class activities despite their similar success rates with students in TC. These results are likely to be related to the instructional design in the MOOC-based FC model, which makes the content of the course more memorable for the learners and helps them internalize the content of the lesson due to increased interaction and discussion among peers.

\section{Discussion of findings for the $2^{\text {nd }}$ research question}

The second research question aimed to reveal pre-service English language teachers' views about integrating a MOOC-based FC model into the ELT program. Based on the qualitative findings, most of the participants said that this could be a good idea, stating that they would like the MOOC-based FC model to be integrated into their ELT program. In accordance with the present results, previous studies have also indicated that participants hold positive views about integrating a MOOC into their traditional classroom lectures (Bruff et al., 2013; Ghadiri et al., 2013; Orsini-Jones, Conde Gafaro, \& Altamimi, 2017; Xinying, 2017; Yousef et al., 2015).

The results are in line with that of Orsini-Jones, Conde Gafaro, and Altamimi (2017) who found in their study that students perceived the MOOC blend as a positive addition to their existing face-to-face courses as they enjoyed the flexibility in the MOOCs that keep additional learning materials within easy reach and provide them with a comprehensive e-learning platform. A possible explanation for these results might be that the participants attached significance to 
communicative aspects of learning across national and cultural borders, which is promoted by MOOCs.

In addition, the model also appears to motivate students to use knowledge more reflectively and keep them engaged in learning far more than a traditional lecture. Moreover, the majority of the students, quite understandably, indicated that the FC approach contributed to their academic achievement as they become more productive and enthusiastic when participating in FC lessons. This result is aligned with that of previous studies (Elmaadaway, 2018; Steen-Utheim \& Foldnes, 2018; Zappe et al., 2009). The participants also seemed to believe that using FC can provide them with some additional qualifications in their professional development. This finding is also consistent with those of Sherrow, Lang, and Corbett (2016) and Al-Zahrani (2015) who found in their studies that there was an increase in the performance of students thanks to the increased interaction with peers, engaging collaborative tasks, and extended inclass time for practice.

However, despite acknowledging the advantages of the MOOC and the FC model and agreeing that it is an effective way to reinforce the subjects in the curriculum and to enhance their learning process, a few of the participants also stated that they would still prefer the TC model due to the fact that they are used to the conventional classes. They were completely against the idea of integrating a MOOC-based FC model into the ELT program, implying that this integration would bring with it extra responsibilities, and it would mean more intensive course content, extra workload, and greater effort. Regardless of their achieved test results, this finding may be explained by students' unwillingness to undertake such a heavy burden and experience a new method in their last year at school.

On the other hand, there were some other respondents, who stated that the integration of a MOOC-based FC model into the ELT program should be free from obligation. This outcome is in line with that of Li et al. (2015) who also found that students with autonomy and freedom to choose their own learning style and have control of their own learning process are happier learners. Likewise, some of the participants in the current study shared their concerns about the role of the instructors, stating that if the instructors do not feel ready to do their job with dedication and devotion and fail to fulfill their obligations, the MOOC-based FC model should not be integrated. Similarly, Bralić and Divjak (2018) and Song, Song, and Wei (2015) warn against students' increased workload, therefore suggesting fine-tuning with learning outcomes and assessment procedures. This rather surprising result can be explained by students' concerns about teachers' readiness to adapt to the new challenges and requirements in order to fulfill their changing roles as well as their willingness to accept new responsibilities because they will need to update their existing knowledge or skills and develop new ones to catch up on the latest technological trends with innovative ideas and attitudes.

Similarly, some participants noted that the issue of integrating the MOOC-based FC model into the ELT program should be dependent on student preferences for specific learning styles. They also indicated that a successful ELT program should address as many various learning styles and learner characteristics as possible. It seems possible that these results are due to some students' belief that responding to different learning styles is likely to provide the best learning outcomes instead of sticking to a uniform approach.

Having said this, though, the overall findings from this study suggest that despite some concerns about students' and instructors' readiness to fulfill their changing roles and adapt to new challenges as well as their willingness to accept new responsibilities and requirements, the 
MOOC-based FC model is generally favored by the majority of the participants, which is in line with some previous studies (Bralić \& Divjak, 2018; Li et al., 2015; Orsini-Jones, Conde Gafaro, \& Altamimi, 2017; Phi, 2018; Xinying, 2017). As a consequence, considering the achieved test results of the students and their high levels of satisfaction, the MOOC-based FC model deserves to be given a chance due to its great potential to promote an active learning network, which is consistent with connectivist principles.

\section{Implications and conclusions}

This study appears to be one of the first attempts to thoroughly examine pre-service English language teachers' perceptions of a MOOC-based FC model. It has been found that even though the model contributed significantly to their academic performances, generally they were cautiously optimistic in their outlook towards the idea of integrating a MOOC-based FC model into the ELT program. These findings suggest students' too much reliance on teachercentered and centralized learning model, which might hinder the development of autonomous learning and autonomous learners. Thus, the findings provide important insights into the role of teachers in supporting different learning styles while at the same time creating a learnerfriendly atmosphere and designing courses that build upon the positive effects of group dynamics, which can enhance learner engagement in classroom activities and outside the classroom.

The current study also highlights the potential usefulness of students' belief in the efficacy of the MOOC-based FC model despite the increased responsibility, devotion and dedication it requires. Hence, the current study highlights the potential usefulness of the MOOC-based FC model in higher education as a good alternative for the modern teacher of the 21 st century with the incredible increase in the use of computers and digital content in schools, universities, and at home. The contribution of this study has also been to confirm that the MOOC-based FC model could constitute a valuable supplement and an ideal complement to traditional face-toface instruction in higher education.

It can thus be suggested that all pre-service and in-service teachers should be informed about the MOOC-based FC model and the effective leverage factors of technology-enhanced education, and they should also be ready to employ new teaching methodologies and different learning models to customize their teaching to the individual needs and expectations of their students.

Finally, considering the unprecedented and global outbreak of the COVID-19 crisis, which led to the near-total closures of schools, universities and colleges worldwide, and forced all policymakers as well as educators to take an action to address new challenges in their education systems, one obvious implication of the current study could be the fact that it provides educators with a conceptual and methodological framework that combines all aspects of online and faceto-face teaching. Moreover, taking into account schools' transition to online learning during the COVID-19 Pandemic, the findings of the present study also suggest that the model presents a well-structured online educational platform with its useful resources to maintain the continuity of the teaching and learning process through the implementation of the MOOC-based FC model.

\section{Limitations and recommendations for future research}

Although it provides some important insights about the pre-service English language teachers' perceptions of the MOOC-based FC model, the current study has some limitations 
that should be considered when interpreting the current findings. The first limitation of the study is based upon the lack of opportunity to compare against a control group not receiving the intervention. The second limitation is the relatively short period of treatment. Longitudinal studies over a longer period of time are expected to yield more valid and reliable results. Third, only senior students in the ELT department were surveyed, and the study was limited by a relatively small number of participants, a total of 27 students. However larger and more inclusive studies are likely to make results more reliable and comparable. Finally, although qualitative data were collected from different participants at different times via two separate open-response questionnaires, some other qualitative tools such as interviews or observations could have been utilized to increase the reliability of the findings.

Based on the findings, the current study has several recommendations for further research. First, further research should focus on comparing the effect of teacher and student readiness for the successful implementation of the MOOC-based FC model. Second, more studies should explore the perceptions of students about the efficacy of teachers in successfully implementing the MOOC-based FC model. Third, experimental investigations should be conducted to find out the impact of MOOCs in enhancing student autonomy and decreasing student dependency on a teacher-centered learning model. Finally, further research on various stakeholders', e.g., practitioners, in-service teachers, teacher trainers, educators, school administrators, and policymakers, perceptions of a MOOC-based FC model should be conducted.

\section{Disclosure of Ethical Issues}

This study meets the principles of research ethics. It has been reproduced from a part of the MA thesis of the first author. Both authors contributed equally to this study and the manuscript at all stages. Informed consent was obtained from all individual participants involved in the study. Authors have no conflict of interest to declare.

\section{References}

Akçor, G. (2018). Exploring the perceptions of pre-service English language teachers of flipped classroom (Master's thesis). Hacettepe University, Graduate School of Educational Sciences, Ankara.

Al-Zahrani, A. M. (2015). From passive to active: The impact of the flipped classroom through social learning platforms on higher education students' creative thinking. British Journal of Educational Technology, 46(6), 1133-1148.

Amiryousefi, M. (2019). The incorporation of flipped learning into conventional classes to enhance EFL learners' L2 speaking, L2 listening, and engagement. Innovation in Language Learning and Teaching, 13(2), 147-161.

Bralić, A., \& Divjak, B. (2018). Use of MOOCs in traditional classroom: blended learning approach. European Journal of Open, Distance and E-learning, 21(1).

Bruff, D. O., Fisher, D. H., McEwen, K. E., \& Smith, B. E. (2013). Wrapping a MOOC: Student perceptions of an experiment in blended learning. Journal of Online Learning and Teaching, 9(2), 187.

Cambridge Assessment English (2019). Teaching English Online. In FutureLearn. Online Course. Retrieved October 7, 2019, from https://www.futurelearn.com/courses/onlinetutoring

Campbell, D. T., \& Stanley, J. C. (1963). Experimental and quasi-experimental designs for research. Boston: Houghton Mifflin Company. 
Chen Hsieh, J. S., Wu, W. C. V., \& Marek, M. W. (2017). Using the flipped classroom to enhance EFL learning. Computer Assisted Language Learning, 30(1-2), 1-21.

Cormier, D. (2008). Rhizomatic education: Community as curriculum. Innovate: Journal of online education, 4(5).

Davies, R. S., Dean, D. L., \& Ball, N. (2013). Flipping the classroom and instructional technology integration in a college-level information systems spreadsheet course. Educational Technology Research and Development, 61(4), 563-580.

de Jong, P. G., Pickering, J. D., Hendriks, R. A., Swinnerton, B. J., Goshtasbpour, F., \& Reinders, M. E. (2020). Twelve tips for integrating massive open online course content into classroom teaching. Medical Teacher, 42(4), 393-397.

Deslauriers, L., \& Wieman, C. (2011). Learning and retention of quantum concepts with different teaching methods. Physical review special topics-physics education research, 7, 1-6.

Elmaadaway, M. A. N. (2018). The effects of a flipped classroom approach on class engagement and skill performance in a Blackboard course. British Journal of Educational Technology, 49(3), 479-491.

Fattah, Said Fathy El Said Abdul (2017), The effectiveness of adopting flipped learning approach in an applied linguistics course for university students, British Journal of English Linguistics, 5(1), 32-43.

Faulkner, G. E. J., \& Taylor, A. H. (2005). Exercise and mental health promotion. In G. E. J. Faulkner \& A. H. Taylor (Eds), Exercise, health, and mental health: Emerging relationships (pp. 1-9). Abingdon, Oxon: Routledge.

Findlay-Thompson, S., \& Mombourquette, P. (2014). Evaluation of a flipped classroom in an undergraduate business course. Business Education \& Accreditation, 6(1), 63-71.

FutureLearn (2019). Teaching English Online. In FutureLearn. Online Course. Retrieved October 16, 2019, from https://www.futurelearn.com/courses/online-tutoring

Flipped Learning Network. (2014). The four pillars of F-L-I-P. Retrieved on May 09, 2020 from www.flippedlearning.org/definition

Ghadiri, K., Qayoumi, M. H., Junn, E., Hsu, P., \& Sujitparapitaya, S. (2013). The transformative potential of blended learning using MIT edX's $6.002 \mathrm{x}$ online MOOC content combined with student team-based learning in class. Environment, 8(14), 1429.

Goldie, J. G. S. (2016). Connectivism: A knowledge learning theory for the digital age?. Medical Teacher, 38(10), 1064-1069.

Heigham, J., \& Croker, R. (Eds.). (2009). Qualitative research in applied linguistics: A practical introduction. Springer.

Hung, H.T. (2015). Flipping the classroom for English language learners to foster active learning. Computer Assisted Language Learning, 28(1), 81-96. doi:10.1080/09588221.2014.967701

Jitpaisarnwattana, N., Reinders, H., \& Darasawang, P. (2019). Language MOOCs: An expanding field. Technology in Language Teaching \& Learning, 1(1), 21-32.

Johnson, L., \& Renner, J. (2012). Effect of the flipped classroom model on a secondary computer applications course: Student and teacher perceptions, questions and student achievement. (Unpublished doctoral dissertation). University of Louisville, Louisville, Kentucky.

Karimi, M., \& Hamzavi, R. (2017). The effect of flipped model of instruction on EFL learners' reading comprehension: Learners' attitudes in focus. Advances in Language and Literary Studies, 8(1), 95-103. 
Kathleen Dunaway, M. (2011). Connectivism: Learning theory and pedagogical practice for networked information landscapes. RSR. Reference Services Review, 39(4), 675-685. doi:10.1108/00907321111186686

Kop, R. and Hill, A. (2008), "Connectivism: learning theory of the future or vestige of the past?", International Review of Research in Open and Distance Learning, Vol. 9 No. 3, available at:www.irrodl.org/index.php/irrodl/article/view/523/1103 (accessed June 20, 2020).

Kropf, D. C. (2013). Connectivism: 21st Century's New Learning Theory. European Journal of Open, Distance and E-learning, 16(2), 13-24.

Li, Y., Zhang, M., Bonk, C. J., \& Guo, Y. (2015). Integrating MOOC and flipped classroom practice in a traditional undergraduate course: Students' experience and perceptions. International Journal of Emerging Technologies in Learning, 10(6).

Love, B., Hodge, A., Grandgenett, N., \& Swift, A. W. (2014). Student learning and perceptions in a flipped linear algebra course. International Journal of Mathematical Education in Science and Technology, 45(3), 317-324.

McLaughlin, J. E., Roth, M. T., Glatt, D. M., Gharkholonarehe, N., Davidson, C. A., Griffin, L. M., ... \& Mumper, R. J. (2014). The flipped classroom: a course redesign to foster learning and engagement in a health professions school. Academic Medicine, 89(2), 236-243.

Orsini-Jones, M., Conde Gafaro, B., \& Altamimi, S. (2017). Integrating a MOOC into the postgraduate ELT curriculum: reflecting on students' beliefs with a MOOC blend. In Q. Kan \& S. Bax (Eds), Beyond the language classroom: researching MOOCs and other innovations (pp. 71-83). Research-publishing.net.

Phi, M. T. (2018). Integrating a MOOC into the MA curriculum: an 'expert' student's reflections on blended learning. In M. Orsini-Jones \& S. Smith (Eds), Flipping the blend through MOOCs, MALL and OIL - new directions in CALL (pp. 25-31). Researchpublishing.net.

Ramlogan, S., Raman, V., \& Sweet, J. (2014). A comparison of two forms of teaching instruction: video vs. live lecture for education in clinical periodontology. European Journal of Dental Education, 18(1), 31- 38.

Sandeen, C. (2013). Integrating MOOCs into traditional higher education: The emerging "MOOC 3.0" era. Change: The magazine of higher learning, 45(6), 34-39.

Sherrow, T., Lang, B., \& Corbett, R. (2016). The flipped class: Experience in a university business communication course. Business and Professional Communication Quarterly, 79(2), 207-216.

Siemens, G. (2005). Connectivism: A learning theory for the digital age. ElearnSpace, everything elearning. Retrieved from http://www.elearnspace.org/Articles/ connectivism.htm

Snowden, K. E. (2012). Teacher perceptions of the flipped classroom: using video lectures online to replace traditional in-class lectures. (Master's thesis). Retrieved from http://digital.library.unt.edu/ark:/67531/metadc149663/m2/1/high_res_d/thesis.pdf.

Song, M., Song, Y., \& Wei, Z. (2015, November). A teaching model of flipped classroom based on mooc. In 2015 Eighth International Conference on Internet Computing for Science and Engineering (ICICSE) (pp. 269-272). IEEE.

Steen-Utheim, A. T., \& Foldnes, N. (2018). A qualitative investigation of student engagement in a flipped classroom. Teaching in Higher Education, 23(3), 307-324.

Strayer, J. F. (2012). How learning in an inverted classroom influences cooperation, innovation and task orientation. Learning Environments Research, 15(2), 171-193. 
Strohmyer, D. (2016). Student perceptions of flipped learning in a high school math classroom. (Doctoral dissertation, Walden University). Retrieved from http://scholarworks.waldenu.edu/dissertations/2178/

Turan, Z., \& Akdag-Cimen, B. (2019). Flipped classroom in English language teaching: a systematic review. Computer Assisted Language Learning, 1-17.

van Manen, M. (2016). Researching lived experience: Human science for an action sensitive pedagogy. Routledge.

Vaughan, M. (2014). Flipping the learning: An investigation into the use of the flipped classroom model in an introductory teaching course. Education Research and Perspectives, 41(1), 25-41.

Xinying, Z. (2017). Researching into a MOOC embedded flipped classroom model for college English Reading and Writing course. In Q. Kan \& S. Bax (Eds), Beyond the language classroom: researching MOOCs and other innovations (pp. 15-27). Researchpublishing.net.

Yaşar, M. Ö. (2020). Can MOOCs Promote EFL Learners' English Communication Skills? Language and Technology, 2(1), 1-15.

Yestrebsky, Cherie L. (2016), Direct comparison of flipping in the large lecture environment. In The Flipped Classroom Volume 2: Results from Practice (pp. 1-18). ACS Publications.

Yilmaz, R. (2017). Exploring the role of e-learning readiness on student satisfaction and motivation in flipped classroom. Computers in Human Behavior, 70, 251-260.

Yin, Y. (2016). Chinese learners' perceptions of MOOCs: A case study (Doctoral dissertation, Heinrich-Heine-Universität Düsseldorf).

Yousef, A. M. F., Chatti, M. A., Schroeder, U., \& Wosnitza, M. (2015). A usability evaluation of a blended MOOC environment: An experimental case study. International Review of Research in Open and Distributed Learning, 16(2), 69-93.

Zappe, S. E., Leicht, R. M., Messner, J., Litzinger, T., \& Lee, H. W. (2009). "Flipping" the classroom to explore active learning in a large undergraduate course. In ASEE Annual Conference and Exposition, Conference Proceedings. 


\section{Appendix A}

\section{FutureLearn MOOC}

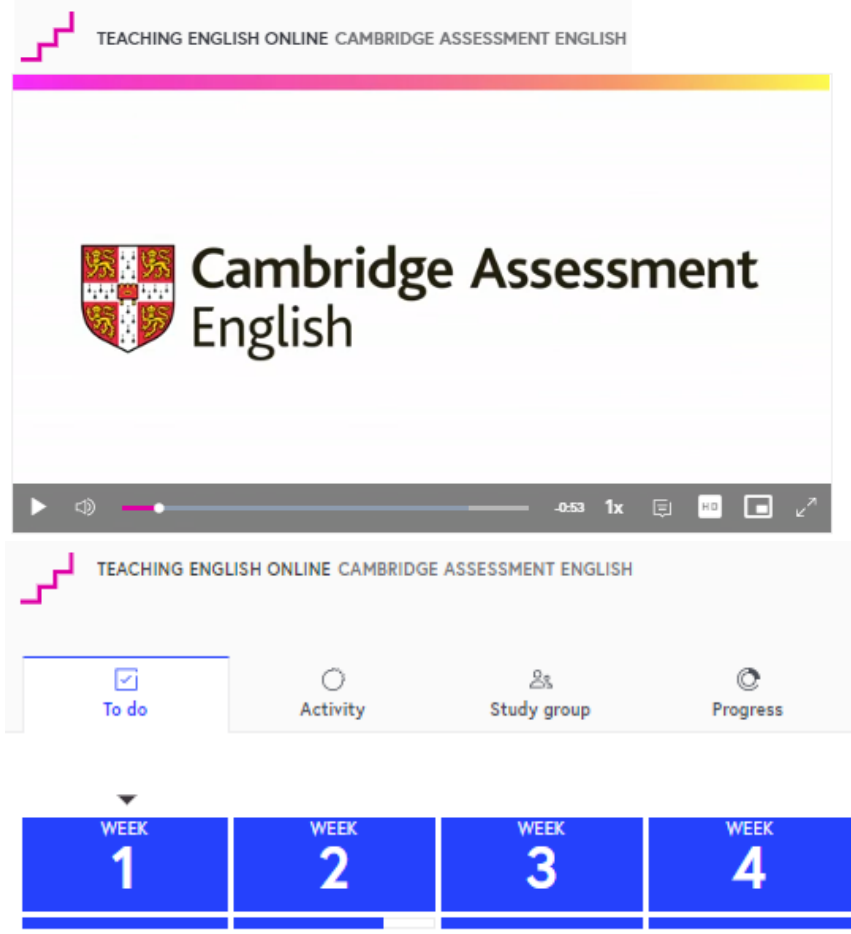

WEEK 1: GETTING STARTED

Welcome to the course

An introduction to the course and to week 1. Getting to know the educators and moderators and introducing yourself.

1.1 INTRODUCtion tO the COURSE AND WELCOME TO WEEK 1 VIDEO (01:43)

1.2 Getting to kNOW US ARTICLE

\section{The online teaching context}

Well talk about the different contexts for teaching online, who you can work for and the different types of students you can teach.

1.3 WHAT DOES IT MEAN TO TEACH ENGLISH ONLINE? VIDEO (02:56)

English

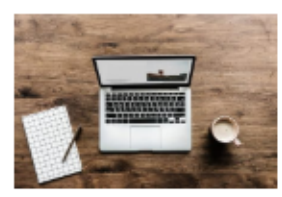

Step - Getting to know your platform

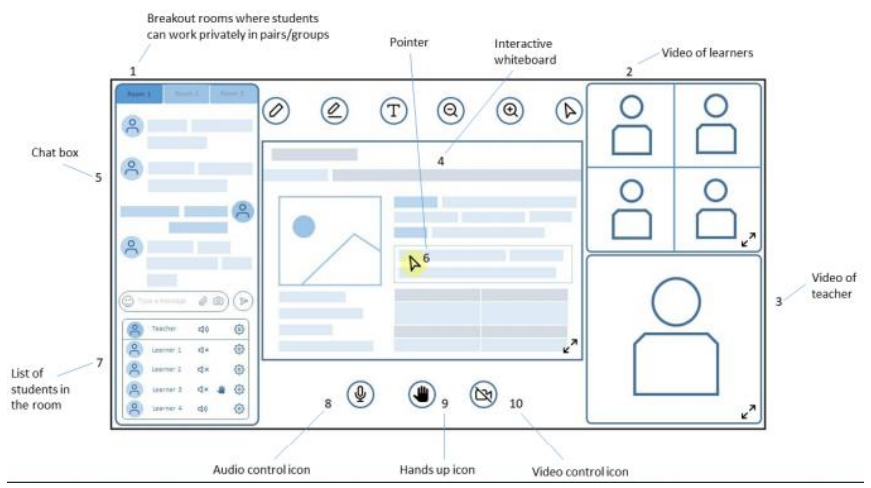


Appendix B

Topics of Teaching English Online FutureLearn MOOC

\begin{tabular}{|c|c|c|c|}
\hline & \multicolumn{2}{|l|}{ Week 1} & \multirow[t]{2}{*}{ Week 2} \\
\hline 1.1. & Introduction to the Course and Welcome To & 2.1. & \\
\hline & Week 1 - Video (01:43) & 2.2 . & Teaching Skills Online vs Teaching Skills \\
\hline 1.2 . & Getting to Know Us - Article & & Face-To-Face - Article \\
\hline 1.3 . & $\begin{array}{l}\text { What Does It Mean to Teach English } \\
\text { Online? - Video (02:56) }\end{array}$ & 2.3. & $\begin{array}{l}\text { How Do Online Reading Lessons Differ from } \\
\text { Face-To-Face Reading Lessons? - Video } \\
(03: 32)\end{array}$ \\
\hline 1.4 . & $\begin{array}{l}\text { Why Become an Online Teacher? } \\
\text { Discussion }\end{array}$ & 2.4. & Reading in a Lesson or for Homework - Article \\
\hline 1.5 . & Working for a Company or Working for & 2.5 . & $\begin{array}{l}\text { Displaying and Sharing Reading Materials - } \\
\text { Video (01:49) }\end{array}$ \\
\hline & Yourself - Quiz & 2.6. & $\begin{array}{l}\text { Outline for an Online Reading Lesson - } \\
\text { Assignment }\end{array}$ \\
\hline 1.6. & $\begin{array}{l}\text { What Equipment Do You Need? - Video } \\
(02: 36)\end{array}$ & 2.7. & Review Another Learner's Assignment - \\
\hline 1.7. & $\begin{array}{l}\text { Getting to Know Your Platform - Video } \\
(03: 43)\end{array}$ & & Assignment Review \\
\hline 1.8 . & $\begin{array}{l}\text { Exploiting Features of a Platform - Video } \\
(05: 35)\end{array}$ & 2.8 . & $\begin{array}{l}\text { Reflect on Your Feedback Assignment - } \\
\text { Reflection }\end{array}$ \\
\hline 1.9. & Researching Different Platforms - Article & 2.9 . & Useful Online Reading Resources - Article \\
\hline 1.10 . & $\begin{array}{l}\text { Other Digital Tools and Resources - Video } \\
(03: 06)\end{array}$ & 2.10 . & $\begin{array}{l}\text { Teaching Listening Skills in Online Lessons - } \\
\text { Video }(02: 45)\end{array}$ \\
\hline 1.11. & Materials and Activities for Online Lessons & 2.11. & A Listening Lesson - Video (05:50) \\
\hline & - Video (02:44) & 2.12. & $\begin{array}{l}\text { Listening Activities for Online Lessons - } \\
\text { Article }\end{array}$ \\
\hline 1.12 . & An Overview of Key Skills - Video (03:31) & 2.13. & $\begin{array}{l}\text { Useful Online Listening Resources - Video } \\
(00: 45)\end{array}$ \\
\hline 1.13. & $\begin{array}{l}\text { Developing Rapport and Motivating } \\
\text { Learners - Video (02:22) }\end{array}$ & $\begin{array}{l}2.14 . \\
2.15 \text {. }\end{array}$ & $\begin{array}{l}\text { Ask Us Your Questions - Article } \\
\text { Video Review of Week } 2 \text { - Video (14:17) }\end{array}$ \\
\hline 1.14. & $\begin{array}{l}\text { Tips for New Online Teachers of English - } \\
\text { Video (04:06) }\end{array}$ & 2.16. & What's On Next Week? - Video (00:48) \\
\hline 1.15 . & Ask Us Your Questions - Article & 2.17. & Test What You Learned - Test \\
\hline 1.16. & Video Review of Week 1 - Video (13:05) & & \\
\hline 1.17. & What's on Next Week? - Video (00:59) & & \\
\hline 1.18. & u've Learned - Test & & \\
\hline & Week 3 & & Week 4 \\
\hline 3.1 . & Welcome to Week 3 Video $(00: 57)$ & 4.1. & Welcome to Week 4 - Video (00:58) \\
\hline 3.2 . & Key Things to Remember When Teaching a & 4.2 . & Online Language Lessons - Video (05:32) \\
\hline & Speaking Lesson - Video (03:28) & 4.3 . & Setting Context - Video (02:54) \\
\hline 3.3 . & $\begin{array}{l}\text { A One-to-One Online Speaking Lesson - } \\
\text { Video }(05: 42)\end{array}$ & 4.4 . & $\begin{array}{l}\text { Useful Online Tools for Setting Context - } \\
\text { Article }\end{array}$ \\
\hline 3.4 . & $\begin{array}{l}\text { A Group Online Speaking Lesson - Video } \\
(08: 22)\end{array}$ & 4.5 . & $\begin{array}{l}\text { Flipping Your Online Classroom - Video } \\
(01: 19)\end{array}$ \\
\hline 3.5 . & Developing Group Cohesion - Article & 4.6. & Practicing Language in Online Lessons - Quiz \\
\hline 3.6 . & $\begin{array}{l}\text { Dealing With Error Correction in Online } \\
\text { Speaking Lessons - Video }(03: 26)\end{array}$ & 4.7. & $\begin{array}{l}\text { Useful Online Tools for Grammar and } \\
\text { Vocabulary Lessons - Article }\end{array}$ \\
\hline 3.7. & $\begin{array}{l}\text { Real-Time Error Correction - You Try It! - } \\
\text { Video (01:48) }\end{array}$ & 4.8. & Attracting Students to Your Online Teaching \\
\hline 3.8 . & $\begin{array}{l}\text { Developing Speaking Skills Outside a } \\
\text { Lesson-Article }\end{array}$ & & Business - Video (04:11) \\
\hline 3.9 . & $\begin{array}{l}\text { Diagnosing Pronunciation Problems - Video } \\
\text { (01:06) }\end{array}$ & 4. & $\begin{array}{l}\text { Running Your Online Teaching Business - } \\
\text { Video (04:52) }\end{array}$ \\
\hline 3.10 . & $\begin{array}{l}\text { Helping Students to Improve Their } \\
\text { Pronunciation - Video }(02: 35)\end{array}$ & $\begin{array}{l}4.10 . \\
4.11 .\end{array}$ & $\begin{array}{l}\text { Testing New Students - Article } \\
\text { Privacy, Security and Copyright - Article }\end{array}$ \\
\hline
\end{tabular}


3.11 .

Useful Online Tools for Developing Pronunciation - Article

3.12 Teaching Writing Skills in Online Lessons Video (01:55)

3.13. An Online Writing Lesson - Video (06:20)

3.14. Giving Feedback on Written Work in a Digital Environment - Video (04:44)

3.15. Useful Digital Tools for Developing Writing Skills - Article

3.16. Ask Us Your Questions - Article

3.17. Video Review of Week 3 - Video (12:46)

3.18. What's on Next Week? - Video (00:38)

3.19. Test What You Learned in Week 3 - Test
4.12.

An Overview of Professional Development Video (03:30)

4.13. Self-Reflection Activities for Online Teachers - Article

4.14. Joining an Online Community of Teachers -

4.14. Video (02:16)

4.15. Ask Us Your Questions - Article

4.16. End-of-Course Video and Further Reading -

4.16. Video (13:10)

4.17. Good Luck! - Article

4.18. Test What You Learned - Test

\section{Appendix C}

\section{First Open-Response Questionnaire}

1. If you would like to explain to us your experience with flipped classroom model with only one word, what would that word be?

2. If you would like to use an analogy to better state your thoughts or feelings about your experience with flipped classroom model, what would that analogy be?

3. Is there something else you would like to add about flipped classroom model?

\section{Appendix D}

\section{Second Open-Response Questionnaire}

1. Considering your MOOC-based flipped learning experience, which approach would you prefer to be used to achieve your curricular goals, conventional or flipped learning? Why?

2. Considering your MOOC-based flipped learning experience, which approach would you prefer to be used in your university courses, conventional or flipped learning? Why?

3. Would you like a MOOC-based FC model to be integrated into the ELT program? 